p. 635]." Now, in the first place, it is possible to question whether the particular time interval chosen by an investigator is indeed that which allows the maximal differentiation of the signal (stimulusconnected transients) from the noise (nonstimulus-connected, "spontaneous" transients). However, it is a distortion to suggest that the signal has failed to be detected at a better-than-chance level by investigators who have used some specified time interval (often 1 to 5 sec following stimulus onset) to define their transient ECL, and this is what Fried et al seem to imply when they state that "there is nobasis for extricating the transient change [Fried et al, 1967c, p. 635]." But, more importantly, if Fried et al really feel that such is the case, why do they then go on to making assertions about transients in their own work? They report that their results "indicate a response decrease" in the "transients," as well as making the rather sweeping claim that "decrease of basal level without accompanying decrease in transient is extremely remote and likewise, failure to obtain change in EL also seldom occurs in conjunction with significant systematic change in transients [Fried et al, 1967c, p. 636]." Thus, while other investigators commonly provide latency criteria for their transient ECL measures on $\mathrm{OR}$ work, Fried et al are content to make assertions about transient ECL while providing neither latency specifications, nor any other statistical evidence to support their claims. Their use of ECL in electrodermal OR work, therefore, should be treated with the same sort of skepticism which I have suggested is appropriate for their use of EL in work on electrodermal adaptation.

\section{REFERENCES}

ALLEN, C. K., HILL, F. A., WICKENS, D. D. The orienting reflex as a function of the interstimulus interval of compound stimuli. Journal of Experimental Psy chology, 1963,65, 309-316.

BERLYNE, D. E., CRAW, A., SALAPATEK, P. H., \& LEWIS, J. L. Novelty, complexity, incongruity, extrinsic motivation, and the GSR. Journal of Experimental Psychology, 1963,66, $560-567$.

FRIED, R., KORN, S., \& WELCH, L. Effect of change in sequential visual stimuli on GSR adaptation. Journal of Experimental Psychology, 1966a, 72, 325-327.

FRIED, R., WELCH, L., \& FRIEDMAN, M. Stimulus novelty and intraseries primacy in GSR adaptation. Perception \& Psychophysics, 1966b, 1, 345-346.

FRIED, R., WELCH, L., FRIEDMAN, M., \& GLUCK, S. Is no stimulus a stimulus? Joumal of Experimental Psychology, 1967a, 73, 145-146.

FRIED, R., WELCH, L., FRIEDMAN, M., \& GLUCK, S. The effect of change in sequential visual stimuli on GSR adaptation: II. The novel stimulus as a disinhibiting stimulus. Perception \& Psychophysics, 1967b, 2, 419-420.
FRIED, R., FRIEDMAN, M., \& WELCH, L. High and low anxiety and GSR adaptation. Psychonomic Science, 1967c, 9, 635-636.

FUREDY, J. J. Novelty and the measurement of the GSR. Joumal of Experimental Psy chology, $1968,76,501-503$.

WOODWORTH, R. S., \& SCHLOSBERG, H.
Experimental psychology. London: Methuen, 1954.

NOTE

1. The preparation of this note was facibtated by Grant APA 303-118-80 from the National Research Council of Canada.

\title{
Effects of praise and censure on normal Ss' performance on a psychomotor task
}

\section{BEVERLEY ROBERTS GOUNARD, I Queen's University, Kingston, Ontario, Canada}

This study investigated performance changes resulting from verbally praising (eight Ss), censuring (eight Ss), or not commenting to (eight Ss) normal Ss as they were engaged in a letter-cancellation task. Censure resulted in significantly faster $(p<.005)$ and better overall $(p<.02)$ performance than praise. Both types of verbal comments produced better overall $(p<.05)$, although not faster, performance than no comments at all. The censured Ss paid for their superiority in terms of a greater number of errors and omissions $(p<.005)$. The differences between the groups were interpreted as resulting from motivational differences.

A cancellation test, in which Ss must cancel out certain letters in a series, represents a classic example of a psychomotor task, i.e., a task "pertaining to the motor effects of cerebral or mental processes [Warren, 1934]." The motor act of cancellation follows perception of the correct stimulus, and thus demands that $S$ adopt a set in a manner analogous to that for a reaction-time test (Yates, 1961). Maximal attention is demanded for best work, and any reduction of attention is reflected directly in the speed or accuracy of the work (Whipple, 1914).

Letter-cancellation tests in the past have been examined for the effects on performance of sex, education (Whipple, 1914), and physical type (Mohr \& Gundlach, 1927;
Klineberg, Asch, \& Block, 1934) but not for the effects of praise and censure. The latter is of interest in considering the effects of social "reward" and social "punishment" in the manipulation of the behavior of individuals engaged in a routine task.

\section{SUBJECTS}

The Ss were 24 female, first-year university students, randomly assigned to the three treatment conditions.

\section{MATERIALS}

Two different pages of typed letters were prepared to form the letter-cancellation test. Twenty-five letters of the alphabet (excluding "Y") were randomly ordered with precaution against the repetition of any letter within two places. Each of the 12 lines of type on each page was composed of 60 consonants and 15 vowels. Each letter was repeated three times in each line of type.

\section{PROCEDURE}

The Ss were tested individually, and after a demonstration, each initially cancelled the vowels on Sheet 1 for a period of $1 \mathrm{~min}$. Before proceeding to Sheet 2, the eight Ss constituting the praised group were told the following: "You seem to be doing very well. Most people don't do half as well as you are doing." Eight others, the censured group, were told: "You don't seem to be doing very well. Most people do twice as well as you are doing." The eight control Ss received no comments on their performance. The comments made in the two experimental groups were designed to be ambiguous as to whether they referred to the Ss' speed or accuracy.

All Ss were then timed for $2 \mathrm{~min}$ as they cancelled the vowels on Sheet 2. By keeping 
Table 1

Summary of Group Scores under Various Scoring Criteria

\begin{tabular}{lccc}
\hline Group & Control & Praised & Censured \\
Total Net Improvement & 15.8 & 68.6 & 241.6 \\
Net Increase in Total & & & 23.0 \\
Errors and Omissions & 18.0 & -1.0 & 350.5 \\
Total Net Speed Gain & 116.0 & 50.0 & 3 \\
\hline
\end{tabular}

the experimental time short, it was hoped to minimize fatigue factors.

\section{RESULTS}

Whipple's method (1914) of scoring cancellation tests by converting speed and accuracy to a single index of efficiency was applied to both sheets. A brief description follows:

$$
\begin{aligned}
& A(\text { index of accuracy })=(c-w) /(c+o) \\
& E(\text { index of net efficiency with } \\
& \text { time limit method })=e A
\end{aligned}
$$

where $\mathrm{e}=$ number of symbols examined $; 0=$ number of letters erroneously omitted; $c=$ number of letters crossed; and $w=$ number of letters wrongly crossed.

For each individual, a net improvement score was obtained by halving the eA score on Sheet 2 and then subtracting the score on Sheet 1. Table 1 shows the mean net improvement scores for each group of Ss. An analysis of variance with orthogonal comparisons revealed that the censured group did significantly better than the praised group $(F=6.07, \quad d f=1 / 21$, $\mathrm{p}<.02$ ), and that the praised and censured groups together did better than the control group $(F=5.25, \mathrm{df}=1 / 21, \mathrm{p}<.05)$.

Using the rank correlation reduced to a normal deviate score, the errors in the three groups were examined. There was no significant relationship between experimental treatment and increase in errors. However, when an analysis of variance was done and orthogonal coefficients were used on errors plus omissions, a significantly greater absolute number of errors and omissions was made by the censured group as opposed to the praised group $(F=40.45$, $\mathrm{df}=1 / 21, \mathrm{p}<.005)$. The censured and praised groups together, however, did not differ significantly from the control group. As can be seen in Table 1, this resulted from an increase in errors and omissions for both the control and censured groups, but a relative stability in the performance of the praised group.

In order to investigate the effect of praise and censure on speed alone, an analysis of variance was carried out on the speed scores and orthogonal coefficients were again used (see Takle 1). The censured group was significantly faster than the praised group $(F=13.19, \mathrm{df}=1 / 21, \mathrm{p}<.005)$, and again, the two experimental groups together did not differ significantly from the control group.

\section{DISCUSSION AND CONCLUSIONS}

The results indicate that the censured zoup of students worked much more quickly but with less care than the praised group. Speed and accuracy were inversely correlated as has been previously reported by Whipple (1914). The question is, however, why Ss responded as they did to praise and censure.

It appears likely that an increase in motivation occurred as a result of censure. As McGeoch \& Irion (1952,p. 199) suggest, stimuli which conflict with a person's conception of himself are likely to arouse fear and anxiety which, in turn, are likely to increase his motivational state.

Letter-cancellation is not a difficult task for Ss of above-average intelligence. However, regardless of the improved overall performance which the increased motivation may have engendered, the decline in accuracy after censure suggests a disorganization in the censured Ss' performance. The praised Ss, having been reinforced for the way in which they were doing the task (however that might have been), showed a stable performance in terms of errors and omissions. Their slight increase in speed and overall performance can probably be attributed to sustained motivation and practice. The control Ss' increase in errors and omissions which almost cancels out their increase in speed in terms of overall performance, possibly resulted from the essentially boring nature of the task.

The praise and censure used could almost be interpreted as knowledge of results since Ss were told that other people did twice as well as they did or only one-half as well. However, the improvement which usually follows knowledge of results (see Munn, 1961), was reflected only in the speed of the censured group and mainly in the accuracy of the praised group. As mentioned above, this might be attributable to a disorganization in the censured Ss' performance and the relative stability in the praised Ss' performance.

Would censure continue to maintain improved overall performance over a period of time? This is questionable in view of the number of errors and omissions and the likelihood that increased motivation would not be maintained. It may be, as Hurlock (1925) found using praise and censure in an elementary classroom arithmetic program, that praise might eventually take the lead.

\section{REFERENCES}

HURLOCK. E. B. The evaluation of certain incentives used in school work. Joumal of Viducational Psy chology, 1925, 16, 145-159.

KLINEBERG, O., ASCH, S. W., \& BLOCK, H. An experimental study of constitutional types. Genetic Psychology Monographs, 1934, 16. 139-2?1.

McGEOCH, J. A., \& IRION, A. The psychology of human learing (Rev. ed.) New York: Longmans, Green, 1952.

MOHR, G. J., \& GUNDLACH, R. H. The relation between physique and pertormance. Journal of Fxperimental Psychology, 1927. 10, 117-157.

MUNN. N. L. Psychology': The fundanentals of human adjustment. Boston: Hough ton Mifflin. 1961.

WARREN, H. C. Dictionary of psychologn: Boston: Houghton Mifflin. 1934.

WHIPPLE, G. M. Manual of mental and physical tests. Part 1: Simple processes. Baltimore: Warwick \& York, 1914.

YAII:S, A. Abnormalities of psychomotor functions. In H. J. Eysenck (Id.), Handbook of abnormal psychology. New York: Basic Books. 1961.Pp. 32-61.

NOTE

1. Now at the University of Waterioo. Waterloo, Ontario. 